\title{
ANÁLISE DE TRILHA PARA AVALIAÇÃO DOS EFEITOS DA GRANULOMETRIA DO SOLO SOBRE O ÍNDICE DE SÍTIO PARA Acacia mearnsii De Wild.
}

Vinicius Morais Coutinho', Carlos Roberto Sanquetta², Ana Paula Dalla Corte ${ }^{2}$, Alexandre Behling ${ }^{2}$, Mateus Niroh Inoue Sanquetta ${ }^{3}$

1. Eng. Florestal, Mestrando em Engenharia Florestal, UFPR (coutinhoengflorestal@gmail.com)

2. Eng. Florestal, Dr(a), Professor do Curso de Engenharia Florestal, UFPR

3. Discente do curso de Engenharia Florestal da UFPR, Bolsista de iniciação científica do CNPq - Brasil

Centro BIOFIX de Pesquisa em Biomassa e Sequestro de Carbono Universidade Federal do Paraná - UFPR

Recebido em: 08/04/2017 - Aprovado em: 10/06/2017 - Publicado em: 20/06/2017 DOI: 10.18677/EnciBio_2017A7

\begin{abstract}
RESUMO
conhecimento acerca do potencial produtivo de um sítio é de extrema importância, principalmente do ponto de vista da tomada de decisão do manejador. Nesse sentido, a influência do meio físico nesse potencial deve ser compreendida e considerada em análises. Este estudo teve como objetivo a construção de curvas índice de sítios, a partir da altura dominante e idade, e avaliação o peso da contribuição da textura do solo na qualidade do sítio florestal para populações de acácia-negra localizadas no município de Cristal - RS. Para tal, foram utilizadas informações de povoamentos com idades entre 9 e 11 anos, localizados na fazenda Ouro Verde. As classes de altura dominante obtidas para os índices de sítio dos povoamentos estudados foram de $18,75 \mathrm{~m}$ para a classe III de sitio, 21,25 m para a classe II e 23,75 m para a classe de sítio I. Quanto à análise granulométrica, notouse a diminuição do teor de areia com o aumento da profundidade, enquanto para os teores de argila verificou-se aumento, a classe textural dos solos foi caracterizada como franco-argilosa para as camadas superficial e subsuperficial. Após a realização da análise de trilha observou-se que as frações granulométricas não exercem influência na qualidade do sítio dos povoamentos de acácia negra, sendo todos os coeficientes inferiores ao índice da variável residual $(0,993)$.
\end{abstract}

PALAVRAS-CHAVE: altura dominante, análise granulométrica, qualidade do sítio.

\section{ANALYSIS OF TRACK FOR EVALUATION OF THE EFFECTS OF GRANULOMETRY OF SOIL ON THE SITE INDEX FOR Acacia mearnsii De Wild.}

\begin{abstract}
The knowledge about the productive potential of a site is extreme important, mainly from the the decision maker of the handler. In this sense, an influence of the physical environment on this potential must be understood and considered in analyzes. The aim of this study was the construction of site index curves, starting from de age and height growth, and evaluating the contribution of soil texture to site index quality, considering the population of black wattle, located in the municipality of Cristal, Rio
\end{abstract}


Grande do Sul State. For that, population informations between 9 and 11 years old, located in Ouro Verde farm were used. The results obtained to dominant height classes to the site population rate studied were $18.75 \mathrm{~m}$ to site class III, $21.25 \mathrm{~m}$ to site class II and $23.75 \mathrm{~m}$ to site class I. As for the granulometry soil analysis, the sand content decrease allied to the depth increase was noted, while for the clay content an increase was verified, the textural class of the soils was characterized as clay loam for the superficial and subsurface layers. After the track analysis, it was observed that particle size fractions do not influence the quality of black wattle population site, with all the coefficients being lower than the residual variable rate.

KEYWORDS: height growth, granulometry soil analysis, site index.

\section{INTRODUÇÃO}

Para conduzir uma floresta com o objetivo de maximizar a sua produção de madeira é indispensável que o manejador tenha conhecimento do potencial produtivo do local onde será implantado o povoamento. Deste modo, é possível detectar diferentes classes de produtividade que são denominadas sítios (SELLE et al., 2009).

Sítio é definido pelos ecologistas como uma unidade geográfica uniforme que se caracteriza por certa combinação estável dos fatores presentes no meio e, em manejo florestal, como um fator de produção primário que tem por capacidade a produção de madeira ou produtos florestais (SCOLFORO, 1993). Segundo CAMPOS \& LEITE (2009), os métodos de avaliação da capacidade produtiva podem ser definidos em três categorias: avaliação da qualidade do lugar pela vegetação indicadora, avaliação por fatores climáticos, edáficos, fisiográficos e bióticos, e avaliação por meio da relação altura dominante e idade, com a definição de índices de local.

Devido à aplicabilidade usual do método de avaliação baseado na relação altura dominante versus idade, é o método mais empregado em estudos sobre capacidade produtiva florestal, pois para a maioria das espécies, áreas de grande capacidade produtiva são também aquelas cujo crescimento em altura é elevado, podendo-se inferir que existe correlação significativa entre a altura dos indivíduos dominantes do povoamento e a capacidade produtiva do lugar (CAMPOS \& LEITE, 2009). No entanto, a capacidade produtiva de uma floresta sofre influência de fatores biológicos, edáficos, climáticos e topográficos, assim, é importante interpretar a influência das propriedades do meio físico sobre a identificação e estratificação de ambientes.

De todos os fatores que afetam a produção, maior consideração tem sido dada às características edáficas, devido à alta correlação entre a propriedades do solo e o crescimento das árvores (BRUM, 1979). No entanto, são escassos os trabalhos que analisam as correlações destes fatores e as interações com os sítios e a capacidade produtiva dos mesmos. Segundo RIGATTO et al. (2005), a classe textural, ou granulometria, dos solos agrega informações importantes na caracterização da capacidade produtiva do sítio. A textura corresponde ás proporções relativas de silte, areia e argila do solo, esta pode ser identificada através do triângulo textural.

No entanto, segundo CHARNET et al. (2008), a análise de correlação simples aponta apenas a presença ou não de associação (positiva ou negativa) entre duas ou mais variáveis, a intensidade e a relação linear ou não linear entre elas. A conclusão sobre a causa e efeito dessas relações não é abordada em estudos de 
correlações, impossibilitando o conhecimento de qual tipo de associação existe entre as variáveis analisadas, pois não dão a devida importância aos efeitos diretos e indiretos das variáveis independentes sobre a variável dependente.

Nesse contexto, estudos sobre a decomposição do coeficiente de correlação podem ser realizados através da análise de trilha (path analysis), desenvolvida e detalhada por WRIGHT (1921 e 1923) e descrita por LI (1975). A análise de trilha é pouco empregada em estudos dentro da engenharia florestal, na sua maioria, emprega-se essa técnica em estudos de melhoramento genético, a exemplo de: KUREK et al. (2001); TEIXEIRA (2011); CRUZ \& CARNEIRO (2006); OLIVEIRA et al. (2015), entre outros.

Diante do exposto, o presente trabalho teve por objetivo realizar a classificação de sítio e avaliar a contribuição da textura do solo, mediante análise de trilha, na qualidade do sítio florestal para povoamentos de acácia-negra.

\section{MATERIAL E MÉTODOS}

\section{Caracterização da espécie}

A Acacia mearnsii De Wild, popularmente conhecida como acácia-negra, é originária da Austrália e caracteriza-se por ser uma árvore de casca e folhagem de coloração escura, sendo a casca rica em tanino (KANNEGIESER, 1990). Pertencente à família Fabaceae, a acácia-negra atinge altura de 10 a 30 metros e tem bom crescimento em solos suficientemente profundos (SHERRY, 1971). No Brasil, a acacicultura tem se tornado uma importante atividade econômica, trazendo consideráveis benefícios para a população de vários municípios do interior do Rio Grande do Sul, sobretudo para pequenos produtores rurais, que as cultivam em sistemas agrossilvipastoris (ABRAF, 2015). O cultivo da espécie atinge área plantada de 160.827 hectares (IBÁ, 2016), ficando somente atrás dos plantios com os gêneros Eucalyptus, Pinus e Hevea (Seringueira). A rotação se estende entre 7 e 10 anos de idade (CALDEIRA et al., 2002; BEHLING, 2016), quando a floresta é colhida e se exporta todo o tronco (madeira e casca).

\section{Caracterização da área de estudo}

Para o desenvolvimento do presente estudo, foram utilizados dados de plantios comerciais de acácia-negra situados no município de Cristal - RS, em propriedade da TANAGRO S/A. Os povoamentos somam 996,8 hectares e estão sob as coordenadas centrais Sul $30^{\circ} 55^{\prime}$ S e $52^{\circ} 10^{\prime} \mathrm{W}$.

Segundo a classificação climática de Köppen, o clima na região é caracterizado como do tipo Cfa, subtropical úmido, sem estiagem, com temperaturas médias mensais oscilando entre $10^{\circ}$ e $22^{\circ} \mathrm{C}$, temperatura média do mês mais quente acima de $22^{\circ} \mathrm{C}$ e a do mês mais frio inferior a $18^{\circ} \mathrm{C}$ e superior a $3^{\circ} \mathrm{C}$ (SANQUETTA et al., 2016). O solo da área de estudo enquadra-se no tipo Planossolo Hidromórfico Eutrófico (Sge), com horizonte superficial e aluvial de textura arenosa ou média, contrastando com o horizonte B de elevada concentração de argila.

\section{Inventário Florestal}

Os dados básicos para o estudo foram obtidos de 91 parcelas temporárias de inventário florestal, com área de $450 \mathrm{~m}^{2}$, distribuídas aleatoriamente sobre o povoamento, em diferentes idades (9 a 11 anos) e condições de sítio. $O$ espaçamento entre árvores é de $3,0 \times 1,5 \mathrm{~m}$, resultando em 2.222 árvores por 
hectare. Em cada uma das parcelas, foram coletadas as informações de DAP (diâmetro à altura do peito) para todas as árvores e HT (altura total) para parte das árvores. As demais alturas foram estimadas por meio da equação hipsométrica:

$$
\frac{D A P^{2}}{\sqrt{H T-1,3}}=4,12209+0,13816 \text { dap }+0,21357 \text { DAP }^{2}
$$

\section{Classificação de Sítio}

A variável utilizada para caracterizar a qualidade do sítio do povoamento florestal foi o Índice de Sítio (IS) dado pela altura dominante (Hdom) aos 7 anos de idade. A altura dominante utilizada no estudo foi a de Assmann (Hdom), representada pela média aritmética das alturas das cem árvores com maior diâmetro por hectare (ASSMANN, 1961). Para a construção das curvas de sítio foi utilizada a equação disponível do software "SISACACIA" (MAESTRI, 1992) (equação 2):

$H_{\text {dom }}=S\left[\frac{(1-\exp (-0,75027 \mathrm{I}))}{\left(1-\exp \left(-0,75027 \mathrm{I}_{\mathrm{ref}}\right)\right)}\right]^{2,812965}$

Em que:

$\mathrm{H}_{\mathrm{dom}}=$ altura dominante;

$S=$ índice de sítio;

I = idade em que se deseja estimar a altura dominante;

$\mathrm{I}_{\text {ref }}$ idade de referência (7 anos).

\section{Análise granulométrica dos solos}

Foram coletadas amostras de solos, em cada uma das parcelas, para análise granulométrica. A análise granulométrica de solos foi realizada pelo laboratório de solos da Universidade Federal de Pelotas (UFPEL), em que foram determinadas as frações de areia, silte e argila nas camadas de 0-20 cm e 20-40 cm. A determinação da classe textural foi obtida por meio do triângulo das classes texturais.

\section{Análise de trilha}

A análise de trilha foi realizada no programa Genes (CRUZ, 2013) e compreendeu na avaliação dos efeitos diretos e indiretos das variáveis independentes (granulométricas do solo) sobre a variável dependente (IS_7), cuja estimativa foi obtida através de equação de regressão linear múltipla, previamente padronizada (regressão parcial padronizada). A padronização das variáveis foi realizada por meio da divisão do desvio de cada variável observada em relação à média pelo desvio padrão da variável (equação 3):

$u_{i}=\frac{x_{i}-X}{\partial x}$

Em que:

$\mathrm{u}_{\mathrm{i}}=$ variável padronizada; 
$\mathrm{X}_{\mathrm{i}}=$ variável observada;

$\bar{X}=$ média da variável observada;

$\hat{\sigma}_{X}=$ desvio padrão.

A variável dependente $Y$ e as variáveis independentes $\left(X_{1}, X_{2}, X_{3}, \ldots, X_{n}\right)$ consideradas neste estudo se relacionam por meio do seguinte modelo (LI, 1975):

$Y_{i}-\bar{Y}=b_{01}\left(X_{1}-\bar{X}_{1}\right)+b_{02}\left(X_{2}-\bar{X}_{2}\right)+b_{03}\left(X_{3}-\bar{X}_{3}\right)+\ldots+b_{0 n}\left(X_{n}-\bar{X}_{n}\right)+\varepsilon$

Em que:

$\mathrm{Y}_{\mathrm{i}}=$ variável dependente ou principal;

$\bar{Y}=$ média da variável dependente;

$\mathrm{X}_{1}, \mathrm{X}_{2}, \mathrm{X}_{3}, \ldots, \mathrm{X}_{\mathrm{n}}=$ variáveis independentes;

$\mathrm{b}_{01}, \mathrm{~b}_{02}, \mathrm{~b}_{03}, \ldots, \mathrm{b}_{0 \mathrm{n}}=$ coeficientes da regressão parcial padronizada;

$\varepsilon=$ variável residual.

De maneira correspondente, tem-se o modelo:

$\frac{\gamma-\nabla}{\sigma_{y}}=b_{01} \frac{\sigma_{x 1} 1}{\sigma_{y}} \frac{X_{1}-Z_{1}}{\sigma_{x 1}}+b_{02} \frac{\sigma_{x 2}}{\sigma_{y}} \frac{x_{2}-X_{2}}{\sigma_{x 2}}+b_{03} \frac{\sigma_{x 3}}{\sigma_{y}} \frac{X_{3}-X_{3}}{\sigma_{x 3}}+\ldots+b_{0 n} \frac{\sigma_{x n}}{\sigma_{y}} \frac{X_{n}-X_{n}}{\sigma_{x n}}+\frac{\sigma_{\varepsilon}}{\sigma_{y}} \frac{\varepsilon}{\sigma_{z}}$

De que se obtém:

$y=p_{01} x_{1}+p_{02} x_{2}+p_{03} x_{3}+\ldots+p_{0 n} x_{n}+p_{\varepsilon} u$

Em que:

$\mathrm{y}=(\mathrm{Y}-\overline{\mathrm{Y}}) / \sigma_{\mathrm{y}}$

$\mathrm{x}_{\mathrm{i}}=\left(\mathrm{X}_{\mathrm{i}}-\overline{\mathrm{X}}_{\mathrm{i}}\right) / \sigma_{\mathrm{xi}}$

$\mathrm{u}=\varepsilon / \sigma_{\varepsilon}$

$\mathrm{p}_{0 \mathrm{i}}=\left(\mathrm{b}_{0 \mathrm{i}} \sigma_{\mathrm{xi}}\right) / \sigma_{\mathrm{y}}$

$p_{\varepsilon}=\sigma_{\varepsilon} / \sigma_{y}$

A decomposição das correlações $r_{0 i}$ em efeitos diretos de $x_{i}$ sobre a variável dependente, expresso por $\hat{}_{0 i}$, e os efeitos indiretos de $x_{i}$ via $x_{j}$, expresso por $\hat{}_{o j} r_{i j}$ é apresentada a seguir: 


$$
\begin{aligned}
& \operatorname{Côv}\left(y, x_{1}\right)=r_{01}=\hat{p}_{01}+\hat{p}_{02} r_{12}+\hat{p}_{03} r_{13}+\ldots+\hat{p}_{0 n} r_{1 n} \\
& \operatorname{Côv}\left(y, x_{2}\right)=r_{02}=\hat{p}_{01} r_{12}+\hat{p}_{02}+\hat{p}_{03} r_{23}+\ldots+\hat{p}_{0 n} r_{2 n} \\
& \operatorname{Côv}\left(y, x_{3}\right)=r_{03}=\hat{p}_{01} r_{13}+\hat{p}_{02} r_{23}+\hat{p}_{03}+\ldots+\hat{p}_{0 n} r_{3 n} \\
& \operatorname{Côv}\left(y, x_{n}\right)=r_{0 n}=\hat{p}_{01} r_{1 n}+\hat{p}_{02} r_{2 n}+\hat{p}_{03} r_{3 n}+\ldots+\hat{p}_{n-1} r_{n-1 n}+\hat{p}_{0 n}
\end{aligned}
$$

Deste modo, foi avaliado qual grupamento, ou quais grupamentos de variáveis, mais explica as variações de $Y_{i} \mathrm{e}$, dentro de cada grupamento, quais as variáveis de maior grau de importância quanto aos efeitos diretos e indiretos, sobre a variável dependente.

Além do coeficiente de determinação obtido a partir do modelo de regressão linear múltiplo, que apresenta o efeito das variáveis independentes sobre $\mathrm{Y}$, a análise de trilha permite determinar o efeito residual $(\varepsilon)$ das variáveis não incluídas no modelo. $O$ efeito da variável residual sobre a variável dependente é dado por:

$\hat{p}_{\varepsilon}=\sqrt{1-R^{2}}$

Segundo LI (1975), o efeito da variável residual serve para analisar se os efeitos diretos ou indiretos das variáveis independentes sobre $Y$ devem ou não ser levadas em conta no estudo. Caso o coeficiente que exprime o efeito direto e indireto das variáveis independentes sobre $\mathrm{Y}$, coeficiente de trilha determinado pelo método de mínimos quadrados, seja menor que o valor residual, significa que esta variável independente deve explicar as alterações na variável principal $(Y)$ apenas indiretamente. Ou seja, esta variável se avaliada individualmente, não é suficiente para explicar as diferenças no crescimento. Por outro lado, um coeficiente de trilha maior que o valor residual aponta que existe efeito direto da variável independente sobre a variável independente (variável principal).

\section{RESULTADOS E DISCUSSÃO}

\section{Classificação de Sítio}

A Tabela 1 apresenta as análises estatísticas descritivas para o conjunto de variáveis obtidas por meio das parcelas de inventário florestal temporária, procedentes de povoamentos de acácia-negra. As árvores das parcelas amostradas apresentaram diâmetro médio de $12,07 \mathrm{~cm}$ com desvio padrão de $4,02 \mathrm{~cm}$, valor mínimo de $1,43 \mathrm{~cm}$ e máximo de $28,01 \mathrm{~cm}$. A altura total média foi de $15,93 \mathrm{~m}$, tendo variado entre $1,49 \mathrm{~m}$ e $21,27 \mathrm{~m}$, com desvio padrão de $3,29 \mathrm{~m}$. Já a altura dominante apresentou uma amplitude variando de $18,49 \mathrm{~m}$ a 23,52 $\mathrm{m}$, com média geral de 20,23 m e um desvio padrão de 0,97 m. A variável do Índice de Sítio aos 7 anos de idade "IS_7" apresentou média de 19,96 m.

TABELA 1. Estatísticas descritivas para as variáveis dendrométricas para acácianegra, no município de Cristal, RS.

Variável $\mathrm{n}$ Média Desvpad Variância CV (\%) E. Padrão Mín. Máx.




\begin{tabular}{lcccccccc}
\hline dap (cm) & 6927 & 12,07 & 4,02 & 16,19 & 33,34 & 0,048 & 1,43 & 28,01 \\
$h t(\mathrm{~m})$ & 6927 & 15,93 & 3,29 & 10,84 & 20,67 & 0,040 & 1,49 & 21,27 \\
hdom $(\mathrm{m})$ & 91 & 20,23 & 0,97 & 0,94 & 4,80 & 0,102 & 18,49 & 23,52 \\
\hline
\end{tabular}

Nota: $\mathrm{n}$ = número de observações; Desvpad = desvio padrão; $\mathrm{CV}(\%)=$ coeficiente de variação; E. padrão = erro padrão.

Determinou-se a idade de sete anos como Idade Índice por estar próxima da idade de rotação e, então, arbitrou-se a divisão em três classes de sítio (Tabela 2). Em trabalhos correlatos, SCHNEIDER \& SILVA (1980) realizaram a classificação de sítio para povoamentos de acácia-negra, tendo sido definidos cinco classes de sítio, com variação de 12 a 20 metros, para uma idade de referência de cinco anos. A mesma metodologia foi aplicada por SCHNEIDER et al. (2001).

TABELA 2. Classes de altura dominante para acácia-negra à idade índice de 7 anos, no município de Cristal, RS.

\begin{tabular}{ccc}
\hline Classe & Intervalo & Índice de Sítio $(\mathbf{m})$ \\
\hline III & $17,5-20,0$ & 18,75 \\
II & $20,01-22,5$ & 21,25 \\
I & $22,51-25,0$ & 23,75 \\
\hline
\end{tabular}

Por meio da equação de sítio obtiveram-se graficamente as curvas de cada classe (Figura 1) e, os limites das alturas dominantes médias, estimadas por idade e classe de sítio estão apresentados na Tabela 3.

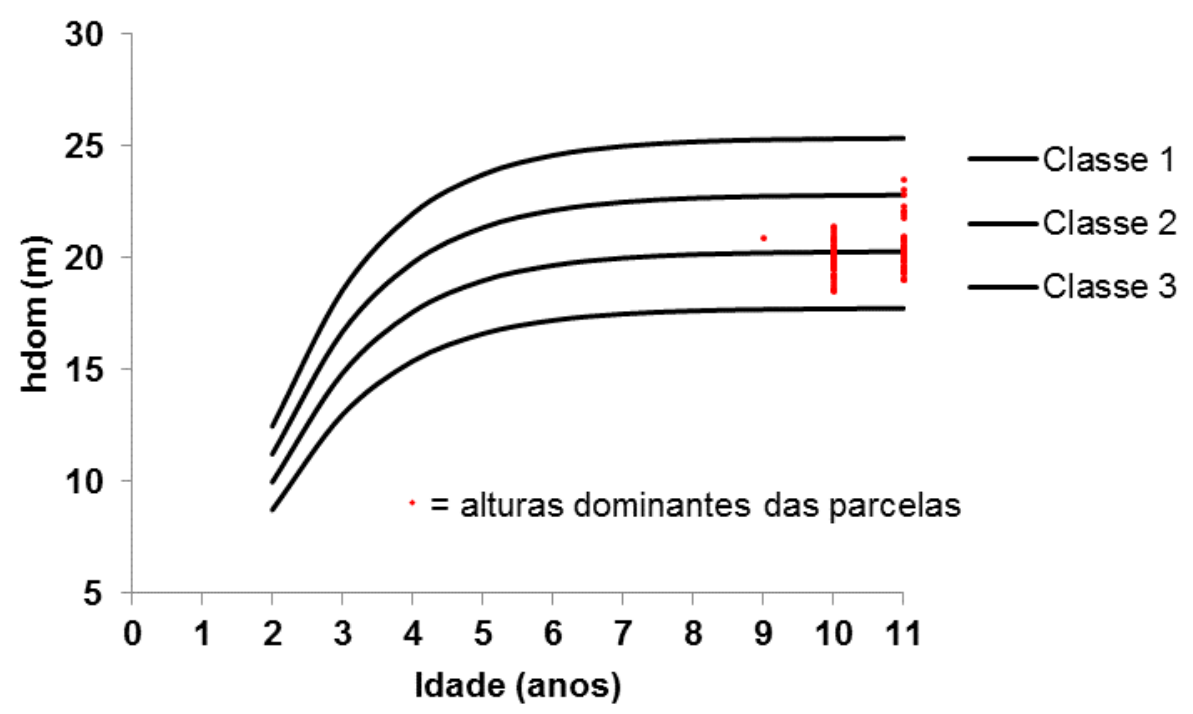

FIGURA 1. Curvas das classes de sítio para acácia-negra, no município de Cristal, RS.

TABELA 3. Limites das alturas dominantes estimadas por idade e classe de sítio para acácia-negra, no município de Cristal, RS.

\begin{tabular}{ccccccc}
\hline \multirow{2}{*}{ Idades } & \multicolumn{2}{c}{ Classe 1 } & \multicolumn{2}{c}{ Classe 2 } & \multicolumn{2}{c}{ Classe 3 } \\
\cline { 2 - 7 } & LS & LI & LS & LI & LS & LI \\
\hline 2 & 12,5 & 11,2 & 11,2 & 10,0 & 10,0 & 8,7 \\
3 & 18,6 & 16,7 & 16,7 & 14,8 & 14,8 & 13,0
\end{tabular}

ENCICLOPÉDIA BIOSFERA, Centro Cientifico Conhecer - Goiânia, v.14 n.25; p.64 2017 


\begin{tabular}{ccccccc}
4 & 22,0 & 19,8 & 19,8 & 17,6 & 17,6 & 15,4 \\
5 & 23,7 & 21,4 & 21,4 & 19,0 & 19,0 & 16,6 \\
6 & 24,6 & 22,1 & 22,1 & 19,7 & 19,7 & 17,2 \\
7 & 25,0 & 22,5 & 22,5 & 20,0 & 20,0 & 17,5 \\
8 & 25,2 & 22,7 & 22,7 & 20,2 & 20,2 & 17,6 \\
9 & 25,3 & 22,8 & 22,8 & 20,2 & 20,2 & 17,7 \\
10 & 25,3 & 22,8 & 22,8 & 20,3 & 20,3 & 17,7 \\
11 & 25,4 & 22,8 & 22,8 & 20,3 & 20,3 & 17,7 \\
\hline
\end{tabular}

Nota: LI = limite inferior; LS = limite superior; destaque em cinza: idade índice.

\section{Análise granulométrica dos solos}

Por meio da análise granulométrica verificou-se que os teores de areia variaram entre $593,30 \mathrm{~g} \cdot \mathrm{kg}^{-1}$ e $790 \mathrm{~g} \cdot \mathrm{kg}^{-1}$, com média de $727,02 \mathrm{~g} \cdot \mathrm{kg}^{-1}$ para a camada superficial $(0-20 \mathrm{~cm})$, para a camada subsuperficial $(20-40 \mathrm{~cm})$ os teores de areia variaram entre $562,90 \mathrm{~g} \cdot \mathrm{kg}^{-1}$ e $803,30 \mathrm{~g} \cdot \mathrm{kg}^{-1}$, com média de 704,62 g. $\mathrm{kg}^{-1}$. Os teores de silte variaram entre $72,10 \mathrm{~g} \cdot \mathrm{kg}^{-1}$ e $240,30 \mathrm{~g} \cdot \mathrm{kg}^{-1}$, com média de $151,73 \mathrm{~g} \cdot \mathrm{kg}^{-1}$ para a camada superficial do solo, a variação de silte na camada subsuperficial foi entre 29,20 g. kg ${ }^{-1}$ e 250,00 g. $\mathrm{kg}^{-1}$, com média de 156,25 g kg-1 g. $\mathrm{kg}^{-1}$. Já para o teor de argila, a camada superficial apresentou variação entre 57,00 g. $\mathrm{kg}^{-1}$ e 219,30 g. $\mathrm{kg}^{-1}$, com média de $121,35 \mathrm{~g} \cdot \mathrm{kg}^{-1}$, e para a camada subsuperficial a variação foi entre

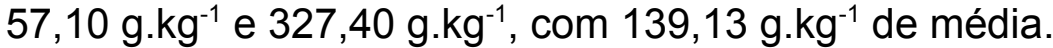

LOURENÇO (1996) realizou análise granumolétrica em Três Barras - SC e observou que o teor de areia diminuiu a medida que a profundidade analisada aumentou, enquanto que, o teor de argila aumentou de acordo com a profundidade.

Tomando como base os valores médios, a classe textural do solo foi classificada como franco arenoso para as camadas superficial e subsuperficial. RACHWAL et al. (2008) estudando a influência das características pedológicas na produtividade de acácia-negra, no município de Butiá - RS, encontraram textura média no horizonte superficial, exceto para o Argissolo Vermelho, que é arenoso. No horizonte subsuperficial a textura se apresentou variável, com Argissolo VermelhoAmarelo e Cambissolo em textura argilosa, enquanto Neossolo Litólico e Neossolo Regolítico encerram a textura média.

\section{Análise de trilha}

A finalidade da análise de trilha foi observar a tendência de associação entre a variável principal (IS_7) e as explicativas (granulometria do solo), em que se podem constatar as influências das características do meio físico no crescimento de acácia-negra. Tal relação tem sido realizada em estudos florestais, no trabalho de BOGNOLA (2007) o autor realizou o desdobramento das correlações entre o índice de sítio e características granulométricas do solo em efeitos diretos e indiretos em duas profundidades $(0-20 \mathrm{~cm}$ e $30-50 \mathrm{~cm})$ para Pinus taeda.

As magnitudes e os sinais dos efeitos diretos e indiretos das variáveis granulométricas sobre o índice de sítio encontram-se na Tabela 4. Por esta tabela nota-se que tanto para a camada superficial $(0-20 \mathrm{~cm})$ quanto para a camada subsuperficial $(20-40 \mathrm{~cm})$, a variável a apresentar os maiores coeficientes de trilha com o índice de sítio (IS_7) foi a fração areia, com índices de $(0,114)$ e $(0,094)$, respectivamente. No entanto, estes valores e os demais coeficientes de trilha se apresentam inferiores ao índice da variável residual $(0,993)$. O coeficiente de determinação $\left(R^{2}\right)$ é inadequado. Desse modo, não há influência das características 
granulométricas do solo na produtividade da acácia-negra, tampouco há uma tendência de que alguma fração granulométrica do solo possa influenciar o crescimento desta espécie. BOGNOLA (2007) em seu trabalho com unidades de manejo para Pinus taeda com base em características do meio físico, observou que do conjunto de variáveis físico-hídricas analisadas apenas a macroporosidade da camada subsuperficial apresentou coeficiente de trilha significativo com o Índice de Sítio.

O conhecimento das variáveis ambientais que atuam na estruturação da floresta, como clima e solo, é de grande importância às atividades florestais. As mudanças climáticas, por exemplo, podem impactar as florestas em diferentes aspectos e, as alterações provocadas no crescimento das florestas podem acarretar diferenças na dinâmica esperada para os povoamentos florestais, tais como a mortalidade e a competição. COUTO \& FERREIRA (1981), analisando a influência de variáveis ambientais no crescimento de Eucalyptus spp em Minhas Gerais e Espírito Santo, concluíram que a altitude foi a variável que mais influenciou no desenvolvimento em altura das espécies plantadas, seguido da deficiência hídrica. Stape et al. (1997), estimando produtividade de povoamentos híbridos de Eucalyptus grandis e Eucalyptus urophylla, concluíram que a produtividade é muito dependente da precipitação e que as características edáficas influenciavam na produtividade por meio da melhoria do aposte hídrico. MACHADO et al. (2014), estudando o efeito de variáveis climáticas no crescimento de Pinus taeda e Araucaria angustifolia, observaram que os incrementos correntes médios (ICM'S) tiveram forte relação com temperatura, pressão atmosférica e fotoperíodo para ambas as espécies.

TABELA 4. Efeitos diretos e indiretos das variáveis granulométricas do solo sobre o índice de sítio, aos sete anos de idade, para acácia-negra

\begin{tabular}{clc}
\hline Variável & \multicolumn{1}{c}{ Efeito } & Estimativa \\
\hline \multirow{2}{*}{ Areia $(0-20 \mathrm{~cm})$} & Direto sobre IS_7 & 0,039 \\
& Indireto sobre IS_7 & 0,075 \\
& Total & 0,114 \\
\hline \multirow{2}{*}{ Silte $(0-20 \mathrm{~cm})$} & Direto sobre IS_7 & $-0,013$ \\
& Indireto sobre IS_7 & $-0,057$ \\
& Total & $-0,071$ \\
\hline \multirow{2}{*}{ Argila $(0-20 \mathrm{~cm})$} & Direto sobre IS_7 & $-0,029$ \\
& Indireto sobre IS_7 & $-0,037$ \\
& Total & $-0,065$ \\
\hline \multirow{2}{*}{ Areia $(20-40 \mathrm{~cm})$} & Direto sobre IS_7 & 0,024 \\
& Indireto sobre IS_7 & 0,070 \\
& Total & 0,094 \\
\hline \multirow{2}{*}{ Silte $(20-40 \mathrm{~cm})$} & Direto sobre IS_7 & $-0,043$ \\
& Indireto sobre IS_7 & $-0,049$ \\
& Total & $-0,092$ \\
\hline \multirow{2}{*}{ Argila (20-40 cm) } & Direto sobre IS_7 & 0,008 \\
& Indireto sobre IS_7 & $-0,035$ \\
& Total & $-0,028$ \\
\hline Coeficiente de determinação & & \\
= &
\end{tabular}




\begin{tabular}{ll}
\hline Efeito da Variável Residual $=$ & 0,993 \\
\hline
\end{tabular}

\section{CONCLUSÕES}

As classes de altura dominante obtidas para os índices de sítio dos povoamentos estudados foram de $18,75 \mathrm{~m}$ para a classe III, $21,25 \mathrm{~m}$ para a classe II e 23,75 m para a classe I. Quanto à análise granulométrica, notou-se a diminuição do teor de areia com o aumento da profundidade, enquanto para os teores de argila verificou-se aumento.

A classe textural do solo foi classificada como franco arenoso para as camadas superficial e subsuperficial. As frações granulométricas não exercem influência na qualidade do sítio dos povoamentos de acácia negra, sendo todos os coeficientes inferiores ao índice da variável residual $(0,993)$. No entanto, conhecer a relação das variáveis ambientais com a qualidade do sítio florestal é fundamental para viabilizar o planejamento da atividade florestal, assim, a modelagem biológica se torna uma ferramenta útil e eficiente na representação da realidade.

\section{REFERÊNCIAS}

ABRAF. Anuário estatístico da ABRAF: ano base 2015. Brasília, 2015. 80 p.

ASSMANN, E. Waldertragskunde. Muenchen: BLV Verlagsgessellschaft, 1961. 435 p.

BEHLING, A. Modelagem da biomassa de árvores para assegurar aditividade dos seus componentes. Curitiba, 2016. Tese (Doutorado em Engenharia Florestal) - Setor de Ciências Florestais - Universidade Federal do Paraná.

BOGNOLA, I. A. Unidades de manejo para Pinus taeda L. no planalto norte catarinense, com base em características do meio físico. Curitiba, 2007. Tese (Doutorado em Engenharia Florestal) - Setor de Ciências Florestais - Universidade Federal do Paraná.

BRUM, E. T. Relações entre altura dominante e fatores do sítio, em povoamentos de Pinus elliottii na região de Ponte Alta do Norte - SC. Curitiba, 1979. Dissertação (Mestrado em Ciências Florestais) - Setor de Ciências Agrárias Universidade Federal do Paraná.

CALDEIRA, M. V. W.; RONDON NETO, R. M.; SCHUMACHER, M. V.; WATZLAVICK. Exportação de nutrientes em função do tipo de exploração em um povoamento de Acacia mearnsii De Wild. Floresta e Ambiente, v. 9, n. 1, p.97-104, 2002.

CAMPOS, J. C. C.; LEITE, H. G. Mensuração Florestal: Perguntas e Respostas. Viçosa: Ed. UFV, 2009, 548 p.

CHARNET, R.; FREIRE, C. A. L.; CHARNET, E. M. R.; BONVINO, H. Análise de modelos de regressão linear com aplicações. Campinas: Unicamp, 2008. 
COUTO, H.T.Z., FERREIRA, C.A.A. Influência de variáveis ambientais no crescimento de espécies/procedências de Eucalyptus spp nos Estados de Minas Gerais e Espírito Santo. Boletim de Pesquisa Florestal, n. 3, p. 9-35, 1981.

CRUZ, C. D.; CARNEIRO, P. C. S.; REGAZZI, A. J. Modelos biométricos aplicados ao melhoramento genético. 4. ed. Viçosa: UFV, 2012. $514 p$

IBÁ - Indústria Brasileira da Árvore - Anuário estatístico, 2016. 100p.

KANNEGIESSER, U. Apuntes sobre algunas acácias australianas:1. Acacia mearnsii De Wild. Ciencia e Investigación Forestal, v. 4, n. 2, p. 198-212, 1990.

KUREK, A. J.; CARVALHO, F. I. F.; ASSMANN, I. C.; MARCHIORO, V. S.; CRUZ, P. J. Análise de trilha como critérios de seleção indireta para rendimentos de grãos de feijão. Revista Brasileira de Agrociência, v. 7, n. 1, p. 29-32, 2001.

LI, C. C. Path analysis - a primer. Boxwood: Pacific Grove, 1975. 346 p.

MACHADO, S. A., ZAMIN, N. T., NASCIMENTO, R. G. M., SANTOS, A. A. P. Efeito de variáveis climáticas no crescimento mensal de Pinus taeda e Araucaria angustifólia em fase juvenil. Floresta e Ambiente, v. 21, n. 2, p. 170-181, 2014. Disponível em: <http://dx.doi.org/10.4322/floram.2014.015>. doi: 10.4322/floram.2014.015.

MAESTRI, R. Estimativa de produção presente e future de volume de madeira e peso de casca para povoamentos de acácia-negra (Acacia mearnsii De Wild). Curitiba, 1992. Dissertação (Mestrado em Ciências Florestais) - Setor de Ciências Agrárias - Universidade Federal do Paraná.

OLIVEIRA, W. B. S.; FERREIRA, A.; GUILHEN, J. H. S.; MARÇAL, T. D. S.; FERREIRA, M. F. D. S.; SENRA, J. F. D. B. Análise de trilha e diversidade genética de Euterpe edulis Martius para caracteres vegetativos e de frutos. Scientia Forestalis, v. 43, n. 106, p. 303-311, 2015.

RACHWAL, M. F. G.; CURCIO, G. R.; DEDECEK, R. A. A influência das características pedológicas na produtividade de acácia-negra (Acacia mearnsii), Butiá, RS. Pesquisa Florestal Brasileira, n. 56, p. 53-62, 2008.

SANQUETTA, M. N. I.; COUTINHO, V. M.; BEHLING, A.; CORTE, A. P. D.; SANQUETTA, C. R. O uso de modelos alométricos tradicionais na estimativa do peso seco aéreo individual para acácia negra. Enciclopédia Biosfera, v.13, n.23, p. 842-842, 2016.2 Disponível em: <http://dx.doi.org/10.18677/Enciclopedia_Biosfera_2016_073>. doi: 10.18677/Enciclopedia_Biosfera_2016_073.

SCHNEIDER, P. R.; SILVA, J. A. Índice de sítio para acácia-negra, Acacia mearnsii De Wild. Brasil Florestal, n.36, p.58-82, 1969.

SCOLFORO, J. R. Mensuração Florestal 4: avaliação da produtividade florestal através da classificação de sítio. Lavras: ESAL / FAEPE, 1993, 138 p. 
SELLE, L. G.; FLEIG, F. D.; VUADEN, E.; ALBERNARD, L. A. J.; BRAZ, E. M. Índices de sítios para Havenia dulcis Thunberg na região central do estado do Rio Grande do Sul, Brasil. Ciência Florestal, v. 19, n. 4, p. 407-423, 2009. Disponível em: <http://dx.doi.org/10.5902/19805098896>. doi: 10.5902/19805098896.

SHERRY, S.P. The black wattle (Acacia mearnsii). Pietermorizburg: University of Natal Press, 1971. 402 p.

STAPE, J. L., GOMES, A. N., de ASSIS, T. F. Estimativa da produtividade de povoamentos monoclonais de Eucalyptus grandis $\mathrm{x}$ urophylla no nordeste do Estado do Bahia - Brasil em função das variabilidades pluviométricas e edáficas. In: IUFRO Conference on Silviculture and Improvement of Eucalypts, Salvador, 1997. Anais. Colombo: EMBRAPA; CNPF, 1997. v. 4, p. 192-198.

WRIGTH, S. Correlation and causation. Journal of Agricultural Research, Washington, v. 20, p. 557-585. 1921.

WRIGTH, S. The theory of path analysis - a replay to Niles' criticism. Genetics, v. 8, p. 239-255. 1923. 